Results 1487 successful LPs were performed from 1996 to 2010.Of these 646 procedures were performed from 1996 to 2000 and 463 samples obtained from 2001 to 2005 .Only 378 LPs were performed from 2006 to 2010. Of those with CSF analysed,967(65\%) were 2 years or younger. $53 \%$ of LPs were performed at night time. Only 18 patients had bacterial meningitis confirmed on $\operatorname{CSF}(1.2 \%)$ from 2001 to 2010 and $60 \%$ were infants.LP was performed before the use of antibiotics in $15 \%$ of cases. Nisseria meningitidis B and Stryptococcus pneumoniae were the leading causes of meningitis (38\%\&27\% respectively).Among those with confirmed meningitis on CSF, serum PCR was positive in $77 \%$ while CSF PCR was positive in $100 \%$ of cases.

Conclusion Incidence of bacterial meningitis is decreasing mainly due to effective vaccination programmes.LP, even in the post vaccination era with early use of emperical antibiotics, still has a role in the diagnosis of meningitis.

\section{EFFECT OF DEXAMETHASONE THERAPY ON THE EXPRESSION OF MACROPHAGE MIGRATION INHIBITORY FACTOR IN CRITICALLY ILL CHILDREN WITH SEPTIC SHOCK}

doi:10.1136/archdischild-2012-302724.1576

MGE Mansour, MAM Tarek, Y Zayton, A Zein. Ain Shams University, Cairo, Egypt

Background and objectives Macrophage migration inhibitory factor (MIF) is a proinflammatory cytokine that plays a major role in the pathogenesis of sepsis. The goal of this study was to determine the effect of exogenous glucocorticoid treatment on MIF expression.

Design and setting: Prospective, randomized, double-blinded, interventional single-center study.

Methods Thirty patients with septic shock were prospectively randomized to receive 3 doses of $0.2 \mathrm{mg} / \mathrm{kg}$ of dexamethasone (Intervention group) or equal doses of saline (Placebo group). Sequential Organ Failure Assessment (SOFA) and Pediatric Logistic Organ Dysfunction (PELOD) scores were recorded daily in both groups. Seven and 28-day Mortality were recorded as early and late endpoints of the study. Baseline and follow-up levels of MIF were measured by ELISA for all enrolled subjects.

Results Mean baseline MIF values were $86 \pm 17,82 \pm 21,10.8 \pm 5 \mathrm{ng} /$ $\mathrm{mL}$ for Intervention, Placebo and control subjects respectively; $p<0.001$. Follow up MIF showed significant reduction in both patients groups compared to baseline levels, with more significant reduction in Intervention group (23\% reduction) compared to Placebo group (13\% reduction); $\mathrm{p}<0.01$. SOFA score showed significant worsening in Placebo group; compared to Intervention group. PELOD score showed significant increase in Intervention group compared to highly significant worsening in Placebo group. Sevenday mortality was significantly higher in Placebo group (53.3\%) compared to Intervention group (20\%); while 28-day mortality showed insignificant change.

Conclusions Early treatment with dexamethasone lead to more significant reduction in MIF levels than placebo, with less worsening of organ dysfunction and improved seven-day mortality with no effect on 28-day mortality.

\section{HDL AND LDL BLO0D LEVELS ARE OPPOSED TO TRIGLYCERIDES AND GLUCOSE IN SEVERE SEPSIS}

doi:10.1136/archdischild-2012-302724.1577

${ }^{1} \mathrm{MD}$ Fitrolaki, ${ }^{2} \mathrm{H}$ Dimitriou, ${ }^{1} \mathrm{~S}$ llia, ${ }^{1} \mathrm{AM}$ Spanaki, 'E Geromarkaki, ${ }^{1}$ E Vasilaki, ${ }^{1} \mathrm{E}$ Tavladaki, 'E Blevrakis, 'G Briassoulis. 'Paediatric Intensive Care Unit, University Hospital of Crete, ${ }^{2}$ Paediatric Haematology Oncology, University of Crete, Heraklion, Greece

Introduction Lipoproteins were shown to neutralize LPS and to exert direct anti-inflammatory actions. Neutrophil CD64-expression (nCD64) was shown to be an early inflammatory sign.
Objectives To examine whether plasma concentrations of high (HDL)- or low (LDL)-density lipoproteins are related to nCD64, triglycerides, glucose, severity of illness (PRISM, PELOD), length of stay (LOS) or mechanical ventilation (LOMV), and mortality in children with sepsis (S) and severe sepsis/septic shock (SS) compared to those with trauma ( $\mathrm{T}$ ) or healthy controls (C).

Methods 48 children were classified into 4 groups of SS, S, T, and C (12 each). Blood samples were collected on 3 consecutive days following admission.

Results On day $1 \mathrm{HDL}, \mathrm{LDL}$, and cholesterol were found to be significantly lower in SS and S compared to C (29.5 \pm 2.7 and $27.3 \pm 4.2$, vs. $58.8 \pm 5.8 \mathrm{mg} / \mathrm{dl}, \mathrm{p}<0.001,33.4 \pm 5.8$ and $66.2 \pm 9$, vs. $98.1 \pm 6.5$ $\mathrm{mg} / \mathrm{dl}, \mathrm{p}<0.001,100.6 \pm 9$ and $125.2 \pm 16$, vs. $171.3 \pm 7 \mathrm{mg} / \mathrm{dl}, \mathrm{p}<0.001$ respectively). Opposite trends followed triglycerides (209 \pm 61 and $151.7 \pm 25$, vs. $71.8 \pm 10 \mathrm{mg} / \mathrm{dl}, \mathrm{p}=0.007)$ and glucose $(117 \pm 8$ and $115 \pm 12$, vs. $83 \pm 3 \mathrm{mg} / \mathrm{dl}, \mathrm{p}=0.002)$. HDL and triglycerides differed between S or SS and T ( $<<0.04)$. Cholesterol, HDL, and LDL were negatively related with $\mathrm{nCD} 64$, procalcitonin, CRP, glucose, LOS, and LOMV ( $p<0.05)$, but not with severity of illness. Glucose was positively related to the LOS and PELOD $(p<0.05)$ and triglycerides with CRP $(p<0.05)$

Conclusions Lipoproteins and cholesterol are markedly reduced in severe sepsis, but not in trauma, and are inversely related to nCD64expression, acute phase proteins, glucose, LOS, and LOMV.

\section{THE CORRELATION BETWEEN C-REACTIVE PROTEIN AND SERIOUS BACTERIAL INFECTION IN A TERTIARY PAEDIATRIC EMERGENCY DEPARTMENT: AN OBSERVATIONAL CASE-CONTROLLED COHORT STUDY}

doi:10.1136/archdischild-2012-302724.1578

1,2,3 MJ Barrett, ' $\mathrm{J}$ Pollock, ${ }^{1} \mathrm{~T}$ Harney, ${ }^{1} \mathrm{~S} J$ Yeung, ${ }^{1} \mathrm{~K}$ Laffan, ${ }^{1} \mathrm{E}$ Clarke, ${ }^{1} \mathrm{~S}$ Darcy, ${ }^{4} \mathrm{~T}$ Grant, 'L Melody, 'P Fitzpatrick, 'S Cashman, 'C Howard, 'Z lqbal, ' $\mathrm{F}$ Taib, 'S McCoy, 'S Walsh, ${ }^{1,2,3} \mathrm{R}$ 0'Sullivan. 'Paediatric Emergency Research Unit, Department of Emergency Medicine, Our Lady's Children's Hospital Crumlin (OLCHC); 'National Children's Research Centre, OLCHC; ${ }^{3}$ Department of Paediatrics; ${ }^{4}$ Public Health and Population Science, University College Dublin, Dublin, Ireland

Background and Aims C-Reactive Protein (CRP) is a common component of the blood panel in children being investigated for the considered diagnosis of serious bacterial infection (SBI). We aimed to correlate CRP values to SBI in a paediatric population.

Methods This is a retrospective study from 2007-2009 of all patients with CRP greater than $100 \mathrm{mg} / \mathrm{L}$. Controls were randomly selected age-matched patients with a CRP less than $100 \mathrm{mg} / \mathrm{L}$. SBI was defined as bacterial meningitis, bacteraemia, urinary tract infection, pneumonia, osteomyelitis, septic arthritis, appendicitis or abscess formation confirmed by microbiological investigations and/ or supporting radiology and ultimate clinical diagnosis.

Results 570/10,191 patients had a CRP $>100 \mathrm{mg} / \mathrm{L}$. 496 patients were controls 424 patients had SBI. A significant difference between the non-SBI group $(n=642), 35 \pm 68 \mathrm{mg} / \mathrm{L}$ (median \pm standard deviation), compared to the SBI group $(\mathrm{n}=424), 141 \pm 87 \mathrm{mg} / \mathrm{L}$, existed. The absolute and ratio risk of SBI increased consistently with rising CRP values (Table 1).

Abstract 1578 Table 1 Incidence, Absolute \& Ratio Risks for SBI

\begin{tabular}{lcccc}
\hline CRP Range & Incidence of SBI & Total cases & Absolute Risk & Ratio Risk \\
\hline $0-20$ & 20 & 248 & $8 \%$ & 0.08 \\
$21-100$ & 39 & 181 & $21 \%$ & 0.27 \\
$101-150$ & 174 & 365 & $48 \%$ & 0.92 \\
$151-200$ & 83 & 134 & $62 \%$ & 1.63 \\
$201-250$ & 43 & 64 & $67 \%$ & 2.03 \\
$251-300$ & 44 & 52 & $84 \%$ & 5.25 \\
$301+$ & 21 & 22 & $95 \%$ & 21.2 \\
\hline
\end{tabular}

